\title{
Pressões da globalização e a resposta criadora*
}

\section{Globalization Pressures and the Creative Response}

Luiz Alberto da Costa Mariz ${ }^{1}$

\begin{abstract}
Resumo
Este artigo aborda a globalização como um complexo processo de institucionalização e examina o potencial da teoria institucional na elucidação das características do fenômeno, em especial, na forma específica como se manifesta nas regiões periféricas. Distingue-se uma globalização hegemônica, que se realiza como difusão institucional a partir dos países cêntricos, de uma globalização contra-hegemônica, constituída de respostas estratégicas de baixo para cima. Com uma síntese entre o "velho" e o "novo" institucionalismos na vertente organizacional, a teoria institucional parece habilitar-se a contextualizar o processo em sua dualidade local/global. Argumenta-se, no entanto, que por excessivo apego à idéia da tendência normal ao equilibrio, essa teoria encontra dificuldades para lidar com os aspectos dinâmicos do fenômeno, particularmente, os que envolvem conflito e mudança de valores. Embora as alternativas de resposta consideradas por Oliver (1991) incluam variadas formas de resistência contra a conformidade às pressões exógenas, este estudo defende, a exemplo de Zimmerman e Zeitz (2002), uma tipologia ampliada de respostas estratégicas. Com a inclusão da resposta da criação, essa tipologia parece espelhar melhor os contrastantes processos da globalização, inclusive, os que implicam mudanças fundamentais no próprio ambiente.
\end{abstract}

Palavras-chave: Mudança institucional; Globalização

\begin{abstract}
This essay investigates globalization as a complex institutionalization process and the potential of institutional theory to clarify the phenomenon, especially in the way it occurs in the peripheral regions. It is distinguished hegemonic globalization, which takes place as an institutional diffusion originated in the central countries, from counter-hegemonic globalization, which comprises bottom-up responses. With a synthesis of the "old" and "new" institutionalism in organization studies, the institutional theory seems able to contextualize the process adequately. However, by excessive attachment to the normal tendency to equilibrium, this theory encounters difficulties in dealing with the dynamic aspects of the phenomenon. Although the alternatives of response considered by Oliver (1991) include varied forms of resistance against conformity, this article defends, following the example of Zimmerman and Zeitz (2002), an expanded typology of strategic responses. By including the creative response, this typology seems more apt to mirror the contrasting processes of globalization, including the ones that introduce fundamental changes in the environment itself.
\end{abstract}

Keywords: Institutional Change; Globalization

1 Doutor em Administração pela Universidade Federal de Pernambuco - UFPE. Professor da Faculdade Boa Viagem. Endereço: Rua Jacobina, 121/601. - Graças. Recife/PE - Brasil -. CEP: 52011180. Email: I.a.mariz@uol.com.br

Artigo recebido em novembro de 2006 e aceito para publicação em janeiro de 2007 


\section{Introdução}

A globalização contemporânea singulariza-se por abarcar, em acréscimo às atividades capitalistas e interestatais, uma ampliada constelação de práticas sociais e culturais. Longe de constituir fenômeno monolítico que aplaina as diferenças entre países e regiões, é característico da globalização, justamente, ser baseada em trocas desiguais entre países cêntricos e periféricos, tanto nas práticas estatais e econômicas, quanto nas socioculturais.

Com base em Santos (2005), é possível divisar dois processos institucionais contrastantes. De um lado, uma globalização hegemônica que se realiza como difusão, a partir dos países cêntricos, de valores e modelos institucionais que são adotados por aquiescência, consciente ou inconsciente, nos países periféricos; de outro, uma globalização contra-hegemônica, constituída de respostas estratégicas originadas nos países periféricos que divergem das pressões institucionais prevalecentes.

Duas questões, centrais ao complexo processo de globalização, defrontam o analista institucional: a dupla contextualização local/global e a dinâmica do processo. Se com uma síntese entre o "velho" e o "novo" institucionalismos a teoria institucional, na vertente organizacional, habilita-se a contextualizar adequadamente o processo da globalização, na condição de abandonar as polarizações entre homogeneidade e heterogeneidade inerentes a essas duas vertentes, essa teoria encontra maiores dificuldades para lidar com os aspectos dinâmicos da globalização.

Grande parte das proposições institucionalistas enfatiza a natureza exógena da mudança, direcionando nosso pensamento a respeito das pressões institucionais em direção à conformidade e à uniformidade (GREENWOOD; HININGS, 1996). O conceito de mudança dominante na teoria institucional mostra-se por demais atrelado à idéia ortodoxa da tendência normal ao equilíbrio, impedindo o exame de mudanças institucionais mais amplas que ocorrem no quadro da globalização contra-hegemônica, a qual acarreta a contestação a valores institucionalizados. $\mathrm{O}$ conceito ortodoxo de mudança institucional não cobre situações históricas extremas, em especial em regiões sujeitas a rápidas mudanças.

Vários autores que adotam a perspectiva institucional vêm buscando superar os limites dessa abordagem no tratamento da mudança institucional. Desde o começo da década de 1990, têm surgido contribuições que visam à integração com perspectivas que valorizam a agência estratégica e colocam no centro das preocupações a dinâmica interna e a ação organizacionais (BECKERT, 1999;GREENWOOD, HININGS, 1996; OLIVER, 1991).

Por exemplo, Oliver (1991), concebe uma tipologia de respostas que busca superar os pressupostos limitantes da teoria institucional, identificando "o repertório completo" de estratégias disponíveis às organizações, em reação às demandas e expectativas institucionais (OLIVER, 1991). Surgem também trabalhos que, procurando compreender e analisar a institucionalização de empreendimentos novatos, concluem pela necessidade de estratégias próximas à "resposta criadora" elaborada por Schumpeter (1968). Nessa situação, mais do que a legitimidade perante o ambiente preexistente, a interação das organizações nascentes visa criar os próprios constituintes, superando as resistências que se antepõem a atividades não rotineiras.

Neste artigo, pretende-se tirar proveito das possibilidades de interação entre a teoria institucional, as concepções de "resposta criadora" de Schumpeter e as reflexões de autores clássicos e contemporâneos que, assumindo o ponto de vista de quem procura soluções para o desenvolvimento socioeconômico das regiões periféricas e semiperiféricas, examina os problemas institucionais que surgem nesses contextos.

A relevância do estudo reside na proposta de avançar nos estudos da mudança institucional, um tema insuficientemente desenvolvido dentro da teoria institucional, contribuindo, com isso, para a adequação do arcabouço dessa teoria ao exame de questões institucionais de regiões periféricas. O estudo procura juntar-se a vozes que se levantam nas arenas acadêmica e política diante do neoliberalismo ainda hegemônico, mas que passa a ser questionado com mais força no plano teórico, por correntes que propõem, como essenciais, algum 
tipo de resposta construída nos próprios países periféricos e semiperiféricos, diante das pressões de globalização, tendo em vista os interesses específicos dessas regiões.

\section{Uma caracterização institucionalista da globalização}

De acordo com Santos (2005), constituem a globalização, conjuntos diferenciados de relações sociais. Portanto, como afirma esse autor, o que existe, a rigor, é uma pluralidade de globalizações. Santos (2005) identifica três constelações de práticas coletivas que formam os pilares do sistema mundial em transição: uma constelação de práticas interestatais, uma constelação de práticas capitalistas globais e uma constelação de práticas sociais e culturais. Essa última constelação, na qual estão incluídos fluxos de culturas, informação e comunicação, era confinada, em grande parte, aos Estados e sociedades nacionais, passando a constituir, na globalização contemporânea, um pilar de importância semelhante à dos outros dois. Comparada com a fase anterior do sistema mundial, a presente fase de transição caracteriza-se por maior complexidade, pois além de estar constituída por maior número de pilares, há nela mais interação entre as constelações de práticas. Marcado por forte componente sociocultural, o conjunto dos processos de globalização caracteriza-se por maior extravasamento dos tradicionais limites dos processos econômicos e estatais (SANTOS, 2005), ganhando relevo os processos cognitivos e os sistemas simbólicos.

A assimetria de poder entre os países cêntricos e os países periféricos enseja trocas desiguais nas constelações de práticas e a existência de "conflitos e, por isso, [de] vencedores e vencidos". (SANTOS, 2005, p. 56). Essas desigualdades e tensões são obscurecidas na visão prevalecente de globalização. Por exemplo, Parker (1999), mesmo reconhecendo potencialidades revolucionárias e tensões nacionais e organizacionais que acompanham a globalização, concebe um mundo único e integrado, cujas fronteiras tradicionais simplesmente se dissolvem sob influências econômicas, sociais, culturais, tecnológicas e dos negócios.

Aprofundando a análise dos contrastes existentes na globalização, Santos (2005) distingue uma globalização hegemônica, operando de cima para baixo, de uma globalização contra-hegemônica, que ocorre de baixo para cima (Ibid., p.71). A globalização hegemônica, por sua vez, desdobra-se em duas "formas de produção". A primeira é o localismo globalizado, processo em que um determinado fenômeno alcança ser difundido mundialmente a partir de uma realidade local, como é o caso da difusão do fast food americano ou da adoção mundial das mesmas leis de propriedade intelectual (Ibid., p.65). O que se observa é que, nessa forma, a globalização concretiza-se predominantemente como uma ocidentalização ou americanização do mundo, "já que os valores, artefatos culturais e os universos simbólicos que se globalizam são ocidentais e, por vezes, especificamente, norte-americanos [...]". (Ibid, p.45).

Como o "global acontece localmente" (SANTOS, 2005, p.74), o localismo globalizado impõe-se ao destino como globalismo localizado, isto é, como o impacto das práticas e imperativos transnacionais nas condições locais (Ibid., p.66). A globalização é, portanto, um processo dual, no qual "os fenômenos dominantes" desvinculam-se do seu âmbito de origem e sofrem uma transformação expansiva, enquanto os "fenômenos dominados" revelam-se como retração, desintegração e desestruturação (Ibid., p.86). Numa perspectiva institucionalista, a globalização hegemônica pode ser definida como um complexo processo de mudança das relações sociais transnacionais, que se realiza como difusão institucional emanando dos países cêntricos, simultaneamente a uma combinação de erosão e transplante institucionais nos países periféricos. É o que parece ocorrer no âmbito das definições de política científica e tecnológica, quando recentes correntes de análise originadas nos países cêntricos difundem mundialmente a idéia de que o mercado é o principal ente regulador da relação universidade-empresa (DAGNINO, 2003).

A globalização contra-hegemônica ocorre, sobretudo, na constelação das práticas sociais e culturais transnacionais que irromperam "com particular pujança nas últimas décadas". (SANTOS, 2005, p.67). Trata-se de uma luta que visa reverter em favor dos países e regiões vitimados, os benefícios do aumento das interações transnacionais. Contrapondo-se às trocas desiguais, à exclusão, à inclusão subalterna e à dependência, a globalização contra-hegemônica se configura como globalização da resistência ao processo dual dos localismos globalizados e dos globalismos localizados. Na globalização contra-hegemônica, buscam-se valores culturais alternativos, por exemplo, com atividades cosmopolitas que articulam resistências localistas, através de 
movimentos literários, artísticos e científicos (Ibid., p.67). É necessário, pois, incluir, no conceito de globalização, a sua forma contra-hegemônica, já que coexistem com a mudança institucional convergente que caracteriza a globalização dominante, respostas estratégicas divergentes direcionadas de baixo para cima.

A dinâmica da globalização se dá em "processos recíprocos de localismos globalizados e de globalismos localizados". (SANTOS, 2005, p.75). A prevalência do princípio do mercado sobre o princípio do Estado e o protagonismo incondicional das empresas multinacionais são exemplos de características que estão presentes globalmente, mas que não vigoram homogeneamente em todo o planeta (SANTOS, 2005). Assim, a globalização é caracterizada por localismos globalizados e globalismos localizados que tendem à homogeneização institucional, mas que se concretizam em trajetórias locais heterogêneas e, ao mesmo tempo, por focos de resistência aos globalismos localizados.

\section{A teoria institucional e a globalização}

Para as organizações de países periféricos que protagonizam atividades no âmbito global, a dinâmica da globalização constitui contextos de referência duais. Nesses contextos, transita a emergente classe dos executivos de que falam Becker e Sklar, que tem um ramo local constituído pela elite empresarial, os diretores de empresas, os altos funcionários do Estado, líderes políticos e profissionais influentes, e um ramo global composto pelos gestores das empresas multinacionais e pelos dirigentes das instituições financeiras internacionais (apud SANTOS, 2005, p.32-33). É nesse grupo de atores transnacionais que Scott (2001) identifica os portadores de elementos cognitivo-culturais globais, nele incluindo "os homens de negócio, os financistas, cientistas e ativistas, bem como um crescente número de ONGs internacionais". (Ibid., p.131).

Quando DiMaggio e Powell (1999) adotam como pressuposto uma transformação histórica no ambiente que transfere a autoridade formal e a capacidade organizativa das elites locais para níveis mais "macro" (Ibid., p.5051), eles privilegiam o ambiente global. Ao mesmo tempo, eles ressaltam como esse ambiente universalizado insinua-se sutilmente nas mentes dos atores organizacionais, dominando as formas de ação e de pensamento. Exemplifica esse processo a forma como é difundida a idéia de que o mercado é o principal ente regulador da relação universidade/empresa, que, de tão penetrante, passa a constituir "senso comum" em escala mundial (DAGNINO, 2003).

No entanto, como vimos, só com a localização é que a globalização se consuma e, para análise dos processos de localização, há que se voltar do "novo" para o "velho" institucionalismo nos estudos organizacionais, pois nele é que se examina como, mediante ações estratégicas, a organização visa "cooptar" o ambiente local. O trabalho tido como o marco do "velho" institucionalismo nos estudos organizacionais é TVA and the grass roots, de Philip Selznick, publicado originalmente em 1949. Ele versa sobre o caso da institucionalização de uma autarquia federal americana, responsável pela implementação de um projeto de desenvolvimento regional numa região pobre dos EUA, o Vale do Tennessee. O estudo examina a política adotada para canalizar um programa federal através de agências locais e, como, no processo, a TVA adquiriu um "caráter distintivo" que refletia a influência da sua região específica de atuação.

É comum se assinalar os contrastes entre o "velho" e o "novo" institucionalismo (por exemplo, DIMAGGIO; POWELL, 1999), porém, no processo da globalização, observa-se também a existência de uma complementaridade entre os respectivos contextos focais. Scott (2001) concebe uma integração de processos de institucionalização em múltiplos níveis que abrange influências desde as instituições globais até o ator e viceversa, passando pelos campos e as organizações locais. Percebe-se conjuntamente "a construção de novas instituições e a transmissão e a difusão de instituições existentes". (SCOTT, 1995, p.140). A formação e a difusão das instituições são vistas como um processo de mão dupla. Modelos institucionais preexistentes nos níveis mais altos (por exemplo, global e campo) provêem contextos nos quais operam organizações locais e seus atores. Ao mesmo tempo, intervêm processos de "baixo para cima", mediante os quais atores e estruturas de nível inferior contribuem para moldar os contextos nos quais operam (SCOTT, 2001, p.196).

O processo da TVA analisado por Selznick envolve o nível local e um nível global (federal) e, conquanto seja o ambiente local o principal foco do estudo, um processo num nível superior ocorre implicitamente, pois é de se 
presumir a existência de outros órgãos locais recebendo pressões semelhantes emanadas do nível federal. Da mesma forma, se a análise em nível local privilegia a diversidade institucional, é presumível um processo simultâneo de homogeneização no nível federal. Podemos estabelecer, assim, um paralelo com o processo de globalização do capitalismo mercantil descrito por Santos, no qual finda por não prevalecer nem a homogeneidade nem a heterogeneidade institucionais e, sim, uma tendência de homegeneização que se consubstancia em trajetórias heterogêneas - como, por exemplo, a do capitalismo social democrático da Suécia ou da Dinamarca, a do capitalismo estatal de alguns países mediterrâneos e a do capitalismo mesocorporativo japonês.

Mesmo no quadro da globalização hegemônica, o isomorfismo enfatizado pelo "novo" institucionalismo é, portanto, uma tendência ou um fenômeno que ocorre apenas parcialmente. No entanto, operando uma síntese com o "novo" institucionalismo, a teoria institucional parece capaz de superar suas limitações no exame dos contextos duais que a globalização produz.

Passando a examinar como essa teoria se habilita a analisar a dinâmica dos processos de globalização, observemos, de saída, que, com DiMaggio e Powell (1991) o conceito de mudança institucional é debilitado, pois praticamente desaparecem os vestígios de qualquer papel ativo das organizações, já que é o ambiente que passa a ser o próprio "ator estratégico" ou "agente"; e "indivíduos, identidades coletivas ou, mesmo, organizações, simplesmente, não habitam o universo social". (PRATES, 2000, p.92-93). No âmbito dos campos, também predomina a passividade. Uma vez que um campo organizacional é estruturado, surgem "forças poderosas" (DIMAGGIO; POWELL, 1991, p. 65), sem origem discernível, que fazem com que as organizações se tornem mais semelhantes entre si. Menciona-se de passagem que o campo passa por um processo de estruturação. A partir daí, é como se a mudança institucional deixasse de existir.

Embora Meyer e Rowan (1991) atribuam um papel mais ativo aos gerentes na gestão da "conformidade ritual", fazendo com que as práticas internas não sigam docilmente a estrutura formal, esses autores acolhem a idéia da autonomia dos mitos que são "dramaticamente" representados e, conseqüentemente, acolhem a idéia da passividade dos agentes organizacionais perante estes. Dessa forma, a possibilidade de reação das organizações sobre o ambiente institucional é atenuada. Nos estudos dos neo-institucionalistas, a mudança institucional limita-se à difusão de padrões, tomados como preexistentes nos ambientes institucionais.

Em Selznick (1957), o conceito de mudança institucional envolve tanto o surgimento de novos padrões quanto o declínio dos velhos. Envolve também uma ativa capacidade de resposta da organização a "um problema colocado por sua história", além de uma conseqüente adaptação que "significativamente muda o papel e o caráter da organização". (Ibid., p.12). Em contraste com a paralisante influência do ambiente sobre a organização, verificada no trabalho de DiMaggio e Powell (1991), Selznick (1957) mostra como a liderança visa reconciliar as disputas internas e as pressões ambientais, acompanhando de perto o modo como o comportamento adaptativo gera modificações no caráter organizacional (Ibid., p.62). Comparativamente, enquanto o "velho" institucionalismo enfatiza mudança organizacional, o "novo" institucionalismo destaca a persistência (CARVALHO; GOULART; VIEIRA, 2004).

A contribuição central de Selznick no estudo sobre a TVA foi a de expandir as explicações dos fenômenos da organização, "a qual pode significativamente ser vista como uma estrutura social adaptativa". (SELZNICK, 1966, p.251). Internamente, os indivíduos resistem a serem tratados como meios e, externamente, a organização enfrenta problemas de adaptação, simplesmente, por existir num ambiente institucional. As tensões resultantes afastam o ordenamento da estrutura formal e o estabelecimento de objetivos de uma orientação estritamente racional. Selznick (1966) sintetiza suas conclusões, afirmando que "a coisa mais importante sobre as organizações é que, apesar de serem elas instrumentos, cada uma delas tem vida por si mesma”. (Ibid., p.10).

Além do significado que assumem para os indivíduos que as compõem, as organizações também são infundidas com valor do ponto de vista do sistema social mais amplo, à medida que simbolizam aspirações das comunidades em que se inserem. Portanto, a institucionalização é o resultado da dinâmica dos "impulsos internos" tanto quanto das "exigências exteriores" do ambiente, num processo comparável à formação de uma personalidade. Dessa forma, a mudança da organização significa a alteração da natureza das suas partes constituintes e o surgimento de uma identidade distinta. 
Em Leadership in administration, publicado em 1957, Selznick, refletindo sobre seus estudos anteriores, concebe a função de "liderança", que para ele não tem o sentido usualmente dado ao termo. Apenas algumas decisões estão ligadas a esse conceito de liderança: as decisões "críticas" relacionadas aos processos de institucionalização, como acontece quando mudanças nas relações de poder entre subunidades organizacionais ensejam uma mudança do "caráter" e do papel de uma organização. Trata-se de uma função que não se confunde necessariamente com a dos tomadores de decisão situados nos altos postos de uma organização. Assim, esse conceito toma a liderança como algo que se torna dispensável quando "os processos de institucionalização passam a ser eliminados ou controlados". (SELZNICK, 1957, p.25). A institucionalização promove estabilidade (SELZNICK, 1957, p.7).

Se, como instrumentos técnicos, as organizações são vistas como ferramentas que podem ser reformadas ou substituídas com relativa facilidade, como instituições, elas obtém uma dimensão "natural" que não é facilmente descartável (SCOTT, 1987, p.494; SELZNICK, 1957, p.18-19). Longe de se restringir à "simples sobrevivência orgânica ou material", o principal objetivo da organização passa a ser o da manutenção da sua integridade institucional (SELZNICK, 1957, p.139-141). Com o conceito de liderança, Selznick evoluiu de uma concepção inicial que tomava a institucionalização como emergente, não intencional, para outra em que ela pode ser vista também como uma intervenção consciente (SCOTT, 1987, p.494).

Esse conceito de mudança institucional como um processo intermitente que conduz à estabilidade aproxima-se da concepção de reprodução institucional formulada por Jepperson (1991). Este autor incorpora ao conceito tradicional de instituição - estrutura social que desempenha seqüências repetidas de atividade, desse modo, constituindo um procedimento organizado e estabelecido - um elemento de dinamismo. As instituições mudam, porém dentro de certos limites, pois lhe são asseguradas estabilidade e sobrevivência através de controles endógenos que são acionados sempre que o padrão estabelecido de interação é rompido. Esses são também ingredientes contidos na concepção de mudança institucional de Selznick: o da atribuição de um dinamismo à instituição (no caso, através da função da liderança) que visa sobretudo à reprodução da estabilidade. No entanto, há que se reconhecer em Selznick, simultaneamente, alguns traços de mudança de "longo prazo" que se consubstanciam na transformação das partes constituintes da organização, como estratégia de adaptação ao ambiente.

Ora, conforme veemente crítica de Cruz (2004) ao institucionalismo neoclássico de North, a mudança institucional não se resume a uma retomada de equilíbrio, tida como certa, após a intercorrência de uma crise. Do ponto de vista das sociedades periféricas e semi-periféricas, nessa abordagem, como afirma Cruz (2004), "fica de fora o principal": "o conflito em sua dinâmica própria" com a possibilidade que acarreta de redefinição de objetivos e, inclusive, de identidades (Ibid., p.58). A concepção institucionalista neoclássica de mudança institucional candidamente prevê que "ao fim e ao cabo, instituições serão criadas, ficando domada a incerteza no quadro de um novo equilíbrio", já que é tomado como certo um resultado que "absolutamente não está de antemão garantido" (Ibid., p. 59). Com efeito, esse conceito de mudança institucional não se coaduna com a globalização contra-hegemônica, pois constitui uma reprodução, enquanto, como afirma ainda Cruz (2004), a disputa envolve "diferentes soluções institucionais para a crise" (Ibid., p. 59).

Se é compreensível, como afirmava Ramos (1965), que a sociologia dos Estados Unidos, por exemplo, priorize a estabilidade, pois, nas condições objetivas daquele país, "a exigência do 'controle social' supõe o interesse em anular as tensões, conservando a estrutura já estabelecida" (Ibid., p. 89), outra é a situação de países como o Brasil. O quadro nacional justifica que se priorize a solução dos antagonismos fundamentais da sociedade brasileira, que requerem "a mudança na qualidade de sua estrutura" (Ibid., p. 89).

Parece ter razão Scott (2001), quando afirma que a maior parte da teorização sobre mudança institucional realizada na teoria institucional até final da década de 1980 privilegiava dois momentos: a formação de novas instituições e a sua difusão entre entidades receptoras. As instituições, uma vez em funcionamento, eram vistas como exercendo seus efeitos, mas sem que elas próprias fossem sujeitas à "mudança adicional” (Ibid., p.181).

A propensão desses estudos pioneiros em não lidar amplamente com a questão da mudança institucional, no entanto, não reside, como pretende Scott (2001), numa elaboração deficiente de agenda de pesquisa, nem num 
descuido de atenção com certos fenômenos. Antes, essas abordagens assumem um caráter conservador por se basearem num conceito de mudança institucional que se subordina ao imperativo da estabilidade. A mudança institucional é sempre um acontecimento pretérito que apenas explica a existência da instituição ou do campo, sem contemplar a possibilidade de a própria instituição vir a sofrer uma transformação radical. Recorrer ao termo institucionalização, como fazem alguns desses autores, parece não passar de um expediente para imprimir ao conceito de instituição a noção de evolução, mas que acaba por confiná-lo à idéia de estabilidade e persistência.

Ao comentar a primeira edição de Institutions and organizations (1995), Hirsch (1997) assinala que a definição ali apresentada por Scott para as instituições - qualificando-as como "estruturas e atividades que provêem estabilidade e significado para o comportamento social" (SCOTT, 1995, p.33) -, aguça a inclinação que a análise institucional tem, de longa data, de privilegiar o problema da ordem, da estabilidade e da sua manutenção. Hirsch (1997) observa ainda que o tema da mudança institucional recebe um tratamento em separado, distante dos temas centrais dessa obra. A ressalva que Scott inclui na definição que consta da segunda edição do livro, a qual estabelece que "instituições por definição conotam estabilidade, mas são sujeitas a processos de mudança, tanto incrementais quanto descontínuos" (SCOTT, 2001, p.48, grifo nosso), substancialmente nada muda. Essa concepção revisada mantém a ênfase na natureza intrinsecamente estável da instituição. A mudança não é considerada uma condição própria da instituição, pois a esta é acrescentada como algo acidental e acessório.

Em resumo, se com uma síntese entre o "velho" e o "novo" institucionalismos a teoria institucional se habilita a contextualizar adequadamente o processo da globalização, reconhecendo a dualidade entre o "global" e o "local", essa teoria, em especial o "novo" institucionalismo, tem dificuldades intrínsecas para lidar com a mudança institucional, tanto no que diz respeito à capacidade proativa das organizações quanto à sua evolução histórica.

\section{Uma ampla tipologia de respostas estratégicas}

Grande parte das proposições institucionalistas enfatiza a natureza exógena da mudança, restringindo o pensamento a respeito das pressões institucionais à conformidade e uniformidade (GREENWOOD; HININGS, 1996). Vários autores, no entanto, vêm buscando saídas para superar esses limites. Desde o começo da década de 1990, vêm surgindo contribuições que parecem apontar para a busca de integração entre a visão institucionalista dominante, em que os fatores exógenos sobressaem, com outras abordagens, seja com o "velho" institucionalismo, seja com outras perspectivas, como a da dependência de recursos e a da agência estratégica, que colocam no centro das suas preocupações a dinâmica interna e a ação organizacional.

Diante das muitas causas determinantes da mudança social e das formas específicas que esta assume nas várias linhas teóricas, Boudon e Bourricaud (2002) afirmam que a sociologia moderna repudia a idéia de que haja apenas uma causa dominante, seja interna ao sistema social, seja originada no ambiente. Numa visão plural, é reconhecida a existência de processos de mudança que são predominantemente endógenos, de outros em que prevalecem os processos exógenos e, ainda, de outros que são um misto dos dois. Em sua maioria, os processos podem ser classificados como mistos, pois afetam não somente as regras de funcionamento do sistema, mas também o seu entorno.

Uma parte expressiva dos trabalhos surgidos na perspectiva institucional vem adotando uma abordagem mais apta a capturar a pluralidade de processos de mudança. Por exemplo, Oliver (1992) inclui elementos organizacionais e ambientais na análise dos antecedentes da desinstitucionalização. No seu esquema teórico, essa autora situa as pressões políticas tanto no interior como no entorno das organizações. Greenwood e Hinings (1996) visam entender a mudança, articulando o estudo da dinâmica política intra-organizacional com o da imersão normativa das organizações em seus contextos, numa abordagem que procura integrar elementos do velho e do novo institucionalismo. Esses autores procuram distinguir processos adaptativos de processos em que a ação organizacional contraria a orientação reinante. 
Nesta seção, focalizamos um trabalho de Oliver (1991) que concebe uma tipologia de respostas estratégicas das organizações às pressões institucionais, que não toma como inevitável a conformidade com a coerção exógena, considerando também alternativas de resposta mais ativas. Identificando "o repertório completo" de estratégias e de táticas disponíveis às organizações, em resposta às demandas e expectativas institucionais (Ibid., p.173), procura-se superar alguns pressupostos que tendem a limitar o alcance da teoria institucional. Na figura 1, tentamos esboçar em forma gráfica os cinco tipos de respostas estratégicas - aquiescência, compromisso, esquivança, desobediência e manipulação - que formam um contínuo entre passividade-atividade diante do ambiente.

Figura 1

Respostas estratégicas

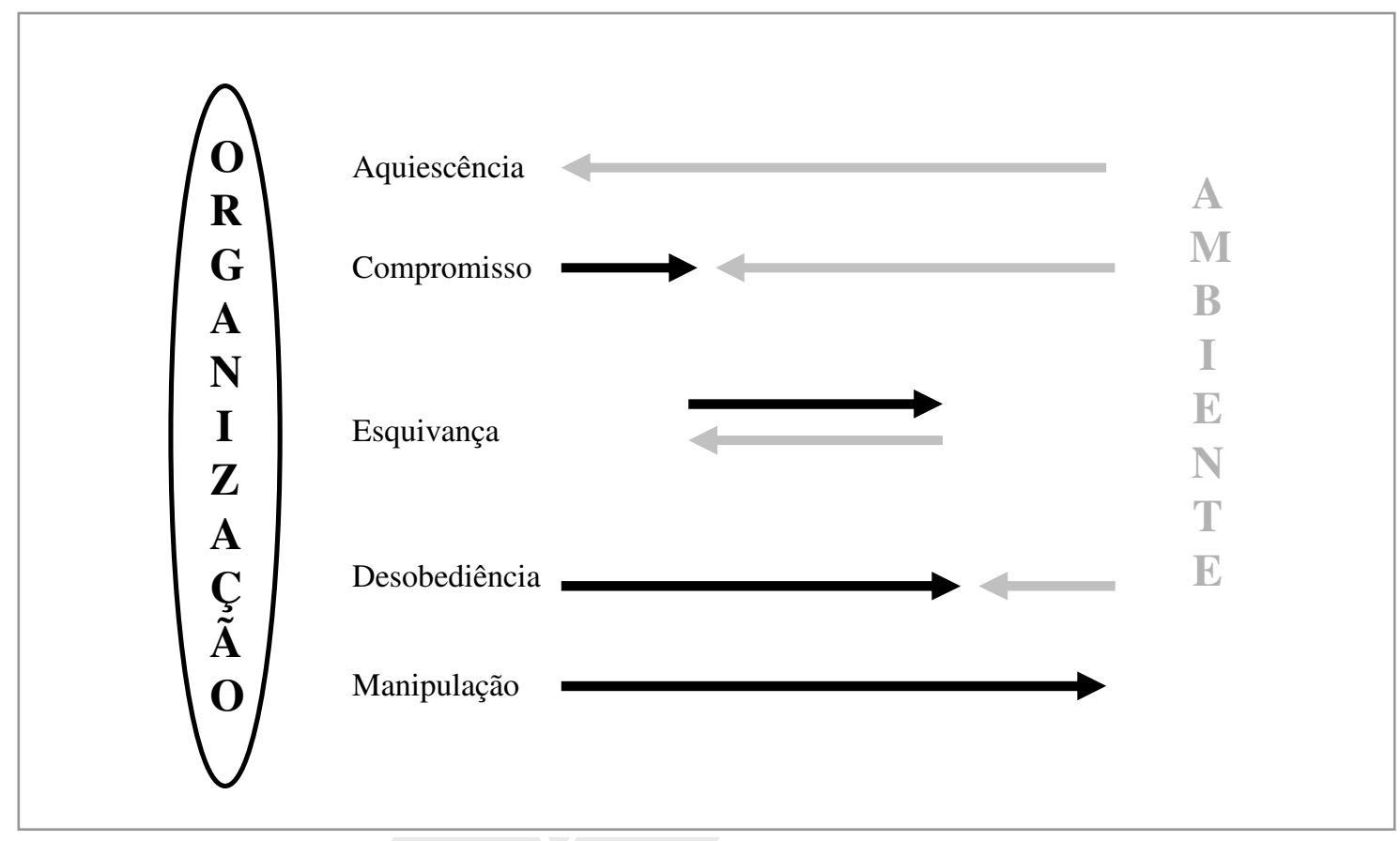

Fonte: criada com base em Oliver (1991).

A aquiescência é o modo usual de resposta das organizações às pressões institucionais. Em especial, quando as normas institucionais atingem a condição de um "fato social", elas passam a ter a força de um hábito para a organização. A organização incorre em aderência inconsciente ou cega a regras e valores e fica, conseqüentemente, impedida de adotar uma resposta estratégica propriamente. Oliver (1991) dá como exemplo a reprodução de papéis amplamente institucionalizados, como os de professor e aluno, com base em definições convencionais sobre essas atividades. O grau de consciência com que as organizações adotam a aquiescência é variável na tipologia de Oliver (1991). A tática de imitação de modelos institucionais que caracteriza o isomorfismo mimético e, mais ainda, o cumprimento de regras e a aceitação de normas institucionais são consideradas mais conscientes do que o hábito. No quadro da globalização hegemônica, a divisão internacional do trabalho entre países cêntricos e periféricos, que reserva para estes o papel de fonte de recursos materiais e de mão de obra barata, ou de exportadores de cérebros, constitui exemplo de estrutura que se reproduz com aquiescência habitual a essa definição de papéis.

No compromisso, a obediência institucional é apenas parcial. As organizações confrontam-se com demandas institucionais conflitantes entre si, ou incompatíveis com os objetivos organizacionais internos, e tornam-se mais ativas na promoção dos seus interesses. 
A esquivança é uma tentativa da organização de impedir a necessidade de conformidade com as pressões institucionais. Elas procuram encobrir a não-conformidade sob uma fachada de aquiescência, ou amortecer o impacto das pressões institucionais, afrouxando vínculos institucionais. Essa modalidade de estratégia corresponde à da "conformidade ritual" (MEYER; ROWAN, 1991), que permite que as práticas internas não sigam as prescrições da estrutura formal. Uma forma extrema de esquivança é a fuga, exemplificada pela instalação de indústrias químicas no Terceiro Mundo, com o objetivo de fabricar produtos proibidos nos países de origem.

A desobediência ${ }^{1}$ é uma forma de resistência mais ativa aos processos institucionais do que as precedentes e representa inequívoca rejeição às normas e expectativas institucionais. $\mathrm{O}$ fato de escolas se conformarem ao conjunto altamente institucionalizado de estruturas e de procedimentos sugere que as pressões institucionais para um entendimento compartilhado dos requisitos educacionais explicam a existência dessas estruturas e desses processos dos sistemas educacionais. Todavia, a teoria institucional não explica a contínua reaparição de escolas alternativas que intentam tirar vantagem de um ativo afastamento das crenças e definições institucionais comumente aceitas sobre o que constitui uma educação efetiva, o que constitui um desafio, uma das táticas da desobediência. O desafio atua no âmbito das crenças e valores e, dessa forma, parece estar presente na globalização contra-hegemônica que se concretiza em movimentos que buscam valores culturais alternativos.

A manipulação, que se subdivide nas táticas da cooptação, da influência ou do controle, é considerada por Oliver (1991) a mais ativa das respostas às pressões institucionais, porque visa à mudança ou ao exercício de poder sobre o conteúdo das próprias expectativas, ou sobre as fontes que buscam expressar ou fazer valer as demandas. Um dos exemplos apresentados por Oliver (1991) é extraído de um estudo de Pfeffer sobre como uma concessionária de energia elétrica obtinha apoio político e legitimidade de setores nos quais a organização estava sob regulação. $O$ estudo concluiu que o meio utilizado pela organização era o de convencer os constituintes institucionais a fazerem parte dos quadros da organização ou do conselho de diretores. Outra forma de cooptação adotada pelas organizações é a exibição de vínculos institucionais já existentes com o intuito de demonstrar adequabilidade e aceitabilidade a outros constituintes externos, dos quais se espera obter aprovação ou recursos.

Selznick (1966), cujo estudo sobre a TVA apresenta elementos tidos por Oliver (1991) como exemplo de manipulação, define cooptação como a situação em que a organização, com o intuito de persuadir grupos de interesses locais a apoiarem seus projetos, publicamente absorve novos elementos, estabelecendo relacionamentos abertamente admitidos e formalmente compostos. Assim, "nomeações para cargos oficiais são realizadas, contratos são assinados, novas organizações são criadas - tudo significando participação no processo de decisão e na administração". (SELZNICK, 1966, p.13).

A influência é uma tática de manipulação que tem matiz cognitivo, pois se dirige mais diretamente a valores e crenças institucionalizados, ou a definições e critérios de práticas aceitáveis ou de desempenho. A tática de controle é vista por Oliver (1991) como uma resposta mais agressiva do que a cooptação e a influência, porque o objetivo organizacional é antes dominar do que influenciar, moldar ou neutralizar as fontes ou processos institucionais.

Na manipulação, as pressões e expectativas institucionais não são tomadas como uma restrição a ser seguida ou desobedecida. Ao invés, "as organizações ativamente alteram, recriam ou controlam as próprias pressões ou os constituintes que as impõem”. (Ibid., p.159). Essa última estratégia alinhada por Oliver (1991) apresenta uma inversão de sentido em relação à primeira, a aquiescência, estando direcionada a dominar ou, ao menos, neutralizar os constituintes que se encontram no ambiente. Nesse sentido, ao invés de implicar resposta, ela parece poder ser conceituada como o exercício das próprias pressões institucionais.

Identificamos entre as estratégias organizacionais extremas de aquiescência e manipulação, um contraste de características que muito se assemelha com o existente entre os comportamentos que adotam ante o ambiente, os tipos schumpetereanos do "simples gerente" e do empreendedor (SCHUMPETER, 1944). A primeira das atividades gerenciais caracterizadas por essa tipologia é a da produção que combina continuamente os mesmos materiais e forças, à qual a maior parte das pessoas se dedica a maior parte do tempo, num exercício marcado 
pelo hábito. Essa atividade se caracteriza por uma conformidade com a forma rotineira de produzir. As alterações ocorrem vagarosamente, através de passos diminutos e quase imperceptíveis. Na rotina ordinária, até o cargo de direção pode ser considerado um "trabalho simples". (SCHUMPETER, 1944, p.132).

Em contraste com a atividade habitual, o outro tipo de atividade tem por objetivo a alteração da maneira como as coisas são realizadas, ou seja, como passar a combinar, de forma diferente, materiais e forças produtivas (SCHUMPETER, 1944, p.107). Enquanto o "simples gerente" limita-se a explorar negócios estabelecidos, buscando o melhor método de produzir entre os já provados empiricamente e que se tornaram familiares, o empreendedor busca o melhor dos método possíveis (Ibid., p.130). Na persecução de um objetivo inédito, o empreendedor segue planos que precisam ser preparados com antecedência. Assim, entre os dois tipos de gestor, "apenas o empreendedor assume uma postura reflexiva sobre as práticas estabelecidas" (BECKERT, 1999, p.786). Enquanto o gerente encontra-se submerso nas práticas rotineiras, o empreendedor se posta "de fora" do modo acostumado de atuar. Entre a atuação costumeira e a consecução de um novo plano, existe, em resumo, uma diferença tão grande quanto entre "construir um caminho ou percorrê-lo" (SCHUMPETER, 1944, p.133).

O contraste entre os comportamentos dos tipos polares de gestores organizacionais de Schumpeter (1944) mostra-se mais acentuado do que aquele observado entre as estratégias extremas categorizadas por Oliver (1991). Comparativamente, enquanto as estratégias alinhadas por Oliver (1991) são modalidades de ação que operam dentro de relações sociais dadas como existentes, a estratégia empreendedora implica o rearranjo das próprias relações e, portanto, apontam para a possibilidade de alterar as redes que constituem o próprio ambiente da organização focal. As idéias básicas de Schumpeter (1944) apresentadas na obra pioneira da Teoria do desenvolvimento econômico vão assumir, mais tarde, maior precisão e uma feição que se expressa no contraste entre a resposta adaptativa e a resposta criadora.

\section{A resposta adaptativa e a resposta criadora}

Como economista, Joseph Schumpeter (1883-1950) está entre os pensadores que mais atenção dedicou à ação empresarial. Todavia, a leitura romântica e individualista que se faz das concepções desse autor sobre o empreendedor não encontra respaldo no teor do conjunto da sua obra (DE PAULA; CERQUEIRA; ALBUQUERQUE, 2004), traindo a freqüente existência de uma "visão parcial, quando não distorcida, do conjunto de suas teorias" (SZMRECSÁNYI, 2002, p.201). Ao adotar uma abordagem multidisciplinar, com grande senso histórico, ele foi praticamente o único grande economista do século XX que logrou incluir a mudança social e institucional no centro das suas preocupações (FREEMAN, 1988).

Ao enfatizar reiteradamente a inovação como a principal fonte de dinamismo do desenvolvimento capitalista, Schumpeter simultaneamente "não rejeitava, e antes tentava incorporar o paradigma do equilíbrio entre as suas forças históricas de mudança" (LOUÇÃ, 2001, p.128). O seu conceito de evolução inclui processos estacionários de equilíbrio juntamente a forças desequilibrantes. Isso parece explicar porque Schumpeter considera tema de investigação fundamental, a interação entre "a influência "modeladora" das formas institucionais e "a influência "explosiva"” da atividade empreendedora (SCHUMPETER, 1968, p.224).

Em obras da maturidade, as reflexões de Schumpeter sobre a função empreendedora conferem atenção aos contextos econômicos mais amplos. Em artigo publicado originalmente em 1947 (SCHUMPETER, 1968), esse autor principia por distinguir as respostas econômicas que, por consistirem em realizar mais (ou menos) a mesma coisa, por assim dizer, configuram reações meramente quantitativas às modificações nas condições daquelas que envolvem fazer "outra coisa". Enquanto o primeiro tipo de resposta é regido pelo princípio da adaptação, o segundo constitui uma resposta criadora (Ibid., p.221-222).

Enquanto a resposta adaptativa afeta apenas o período de transição, deixando que o resultado final seja ditado pelas condições iniciais, a resposta criadora se insere no curso do desenvolvimento histórico, modelando o curso subseqüente dos acontecimentos. Assim, "mudam definitivamente as situações sociais e econômicas", ou de forma ainda mais categórica, são criadas "situações a partir das quais não existem pontes que as liguem às situações que existiriam na sua ausência". (Ibid., p.222). 
Schumpeter (1968) nota que a superação das resistências do meio ambiente a uma ação que segue caminhos ainda não trilhados é uma das atividades empreendedoras de destaque. $\mathrm{O}$ ambiente opõe resistências que variam conforme as condições sociais, desde a simples recusa - seja de financiamento, seja da compra de uma coisa nova - até mesmo o ataque físico ao homem que tenta produzi-la (SCHUMPETER, 1950). Há que se incluir, ainda, como um tipo de resistência ambiental, o desprezo pela própria atividade empresarial, que acomete as sociedades de forma variada.

Ora, parece evidente a inter-relação entre essas questões e as relações de poder que vigoram numa determinada sociedade. Numa reflexão sobre a criatividade no contexto dos países periféricos, Furtado (1978) lembra que está implícita na capacidade de se modificar o meio em que se atua e na presença de agentes privilegiados com capacidade de iniciativa e visão globalizadora. O poder desses agentes tanto pode acionar a modificação do contexto em que atuam, quanto evitar que outros o modifiquem contra seus interesses (Ibid., p.17).

Tratando da criação de empresas num setor industrial novo, tendo em conta que esses novos empreendimentos registram pouco desempenho passado que possa servir de base de legitimação, Zimmerman e Zeitz (2002) propõem uma ampliação do elenco de estratégias que, além de conter categorias afins às de Oliver (1991), inclui a estratégia de criação. Esta envolve "o desenvolvimento de algo que ainda não existe no ambiente" (ZIMMERMAN; ZEITZ, p.425) e constitui, para os autores, a estratégia mais potente, pois afeta a criação de novos valores, crenças, modelos e normas. Por demandarem mudanças nas práticas organizacionais e, simultaneamente, a "criação" do próprio ambiente em que se buscará legitimidade, esses exemplos convergem para a resposta criadora schumpetereana.

\section{Considerações finais}

Este artigo principiou por distinguir dois padrões básicos de resposta estratégica aos processos de globalização contemporânea. Enquanto na globalização hegemônica, a difusão institucional oriunda dos países cêntricos se complementa em um consentimento de transplante institucional nos países periféricos, na sua forma contrahegemônica, a globalização enseja respostas divergentes, de baixo para cima, que apontam para mudanças radicais nas relações entre os agentes envolvidos.

A globalização hegemônica pode ser entendida como um compartilhamento de valores, normas e entendimentos, superposto à cooptação, que é exercida a partir dos "centros dinâmicos". Compartilhamento de valores e normas predispõe os atores periféricos a seguirem as "normas invisíveis, dadas como certas" (OLIVER, 1991, p.152), caracterizando um hábito. A aquiescência que ocorre nesse caso pode conter comportamentos mais conscientes, como a imitação de modelos institucionalizados e a aceitação e cumprimento de regras e normas. Já a cooptação manifesta-se com ações práticas exercidas em nível local, para atender interesses locais, o que permite a consumação da globalização com traços peculiares à região em que o processo opera.

A globalização contra-hegemônica constitui uma inovação. Como exemplo, tomemos de Herrera (1979) a concepção de um sistema de pesquisa e desenvolvimento em países periféricos, com objetivo de produzir o conhecimento $\mathrm{e}$ as tecnologias necessárias ao desenvolvimento autônomo e auto-induzido. Esse empreendimento envolve a adoção de uma metodologia de pesquisa que torne os sistemas de pesquisa e desenvolvimento compatíveis com um novo enfoque relativo ao papel da ciência e do cientista na sociedade. Conforme salienta Herrera (1979), essa proposta apóia-se na participação social nas decisões do sistema de pesquisa e desenvolvimento, participação que dependerá de uma transformação do ambiente local. O conjunto dessas propostas parece coadunar-se com a "resposta criadora" concebida por Schumpeter, pois abrange as mudanças que ocorrem no âmago da organização e no ambiente.

Ao discutirem a evolução da concepção sobre os ambientes, Carvalho e Vieira (2003) notam como, deixando de serem considerados "meras categorias residuais" e tornando-se "tudo o que estava do outro lado da organização" (Ibid., p.28), os ambientes passaram a ser enfocados de modos diferentes, e mesmo divergentes, nos estudos organizacionais. Duas perspectivas vieram a sobressair, uma defendendo que as pressões ambientais controlam as ações organizacionais e a outra, ao invés, que são as organizações que controlam o 
ambiente. Enquanto a aquiescência corresponde à primeira perspectiva, pois constitui uma pressão unilateral exógena, a criação é afim à segunda, pois pressupõe uma ação unilateral direcionada da organização para o ambiente. No entanto, se não tomamos essas estratégias como eventos excludentes, mas como ações que se alternam ou complementam, observamos que a estratégia de criação provê a explicação que falta, em DiMaggio e Powell (1991), para a misteriosa origem dos valores preexistentes no ambiente. Com a estratégia da criação, o ciclo se fecha, pois são organizações que moldam valores no "ambiente" que, afinal, é por elas constituído.

Em seu conjunto, a obra de Schumpeter afasta-se das concepções econômicas ortodoxas, que são unilateralmente apegadas à idéia de tendência normal ao equilíbrio. Ao levar em consideração o ambiente social mais amplo, a teoria institucional também se afasta de concepções similares no domínio da sociologia, mas pelo fato destas se apegarem em demasia à noção do agente racional. Enquanto a teoria institucional ataca as concepções clássicas pelo acento exagerado dado à racionalidade, Schumpeter vai discordar das mesmas concepções, por não levarem suficientemente em conta as possibilidades de ação. A complementaridade entre esses enfoques pode abrir caminho para um exame compreensivo da globalização, superando os limites da "teoria institucional" em cobrir situações extremas de crise e conflito agudo, das quais podem emergir novas formas institucionais, bem como redefinições do próprio contexto em que estas se inserem.

A globalização constitui um complexo processo com o qual contribuem as interações que as organizações travam em nível transnacional. Sua natureza, hegemônica ou contra-hegemônica, principia a caracterizar-se nos casos específicos de pressões e respostas estratégicas que atravessam vários níveis, desde o individual até o global, passando pelo organizacional e o dos campos. O argumento aqui apresentado indica que uma tipologia de estratégias que integre a resposta criadora às táticas e estratégias institucionais arroladas por Oliver (1991) parece oferecer um quadro mais apto para depreender os dinâmicos e conflitantes processos de globalização, em especial os que ocorrem nos países periféricos. 


\section{Referências}

BECKERT, J. Agency, entrepreneurs and institutional change. The role of strategic choice and institutionalized practices in organizations. Organization Studies, v.20, n.5, p.777-799, 1999.

BOUDON, R.; BOURRICAUD, F. Dicionário crítico de sociologia. 2.ed. São Paulo: Editora Ática, 2002.

CARVALHO, C.; VIEIRA M. Contribuições da perspectiva institucional para análise das organizações: possibilidades teóricas, empíricas e de aplicação. In: CARVALHO, C.; VIEIRA M. Organizações, cultura e desenvolvimento local. Recife: Edufepe, 2003.

; GOULART, S.; VIEIRA M. A inflexão conservadora na trajetória histórica da teoria institucional. In: ENCONTRO DA ANPAD, 28. 2004, Atibaia. Anais Atibaia, SP: Anpad, 2004.

CRUZ, Sebastião C. Velasco e. Globalização, democracia e ordem internacional: ensaios de teoria e história. Campinas: Unicamp; São Paulo: Unesp, 2004.

DAGNINO, Renato. A relação universidade-empresa no Brasil e o "argumento da hélice tripla". Revista Brasileira de Inovação, v.2, n.2, p.267-307, jul./dez. 2003.

DE PAULA, J. A.; CERQUeIRA, H. G.; ALBUQUERQUE, E. M. 0 empresário na teoria econômica. Revista de Economia Política, v.24, n.4, p.563-583, out./dez. 2004.

DiMAGGIO, P.; POWELL, W. The iron cage revisited: institutional isomorphism and collective rationality in organizational fields. In: POWELL, W.; DiMAGGIO, P. The new institutionalism in organizational analysis. Chicago: University of Chicago Press, 1991. [publicado originalmente em 1983].

Introducción. In: POWELL, W.; DiMAGGIO, P. El nuevo institucionalismo en el análisis organizacional. México: Fondo de Cultura Económica, 1999.

FONSECA, V. A abordagem institucional nos estudos organizacionais: bases conceituais e desenvolvimentos contemporâneos. In: VIEIRA, M. M. F.; CARVALHO, C. A. (Org.). Organizações, instituições e poder no Brasil. Rio de Janeiro: FGV, 2003.

FREEMAN, Christopher. Introduction. In: DOSI, G. et al. (Ed.). Technical change and economic theory. Londres: Pinter, 1988.

FURTADO, Celso. Criatividade e dependência na civilização industrial. Rio de Janeiro: Paz e Terra, 1978.

GREENWOOD, R.; HININGS, C. R. Understanding radical organizational change: bringing together the old and the new institutionalism. Academy of Management Review, v.21, n.4, p.1002-1047, out. 1996.

HERRERA, Amilcar 0. Um novo enfoque do desenvolvimento e o papel da ciência e da tecnologia.[texto apresentado em seminário internacional, no ano de 1979, original em inglês, tradução e adaptação de Renato Dagnino].

HIRSCH, P. Sociology without social structure: neoinstitutional theory meets brave new world. The American Journal of Sociology, v.102, n.6, p.1702-1723, May 1997.

JEPPERSON, Ronald L. Institutions, institutional effects and institutionalism. In: POWELL, W.; DiMAGGIO, P. The new institutionalism in organizational analysis. Chicago: University of Chicago Press, 1991.

LOUÇÃ, Francisco. Coevolução em sistemas sociais: a emergência de novos conceitos sobre tecnologia e complexidade. In: CUNHA, M. P.; FONSECA, J. M.; GONÇALVES, F. (Org.). Empresas, caos e complexidade: gerindo à beira de um ataque de nervos. Lisboa: RH, 2001.

MEYER, J. W.; ROWAN, B. Institutionalized organizations: formal structure as myth and ceremony. In: POWELL, W.; DiMAGGIO, P. The new institutionalism in organizational analysis. Chicago: University of Chicago Press, 1991. [publicado originalmente em 1977].

OLIVER, Christine. Strategic responses to institutional processes. Academy of Management Review, v.16, n.1, p.145-179, Jan. 1991.

The antecedents of deinstitutionalization. Organization Studies, v.13, n.4, 1992.

PARKER, Barbara. Evolução e revolução: da internacionalização à globalização. In: CLEGG, S.; HARDY, C.; NORD, W. Handbook de Estudos Organizacionais. São Paulo: Atlas, 1999. v.1.

PRATES, A. Organização e instituição no velho e novo institucionalismo. In: RODRIGUES, S.; CUNHA, M. Estudos organizacionais: novas perspectivas na administração de empresas. São Paulo: Iglu, 2000.

RAMOS, A. G. A redução sociológica. 2.ed. Rio de Janeiro: Tempo Brasileiro, 1965.

SANTOS, Boaventura. Os processos da globalização. In: A globalização e as ciências sociais. 3.ed. São Paulo: Cortez, 2005. 
SCHUMPETER, J. Teoría del desenvolvimiento económico. México: Fondo de Cultura Económica, 1944. Capitalism, socialism and democracy. New York: Harper and Brothers, 1950.

1947.]. La respuesta creadora en la historia económica. In: Ensayos. Barcelona: Oikos-Tau, 1968. [originalmente publicado em

SCOT, W. R. The adolescence of institutional theory. Administrative Science Quarterly, v.32, n.2, p.493-511, dec. 1987. . Institutions and organizations. Thousand Oaks: Sage, 1995. Institutions and organizations. Thousand Oaks: Sage, 2001.

SELZNICK, P. Leadership in administration. New York: Harper and Row, 1957. TVA and the grass roots. New York: Harper and Row, 1966.

SZMRECSÁNYI, Tamás. Idéias fundadoras - apresentação. Revista Brasileira de Inovação, v.1, n.2, p.201-202, jul./dez. 2002.

ZIMMERMAN, M.; ZEITZ, G. Beyond survival: achieving new venture growth by building legitimacy. Academy of Management Review, v.27, n.3, p.414-431, July 2002.

\footnotetext{
* Este artigo é uma revisão de trabalho apresentado no $30^{\circ}$ Encontro da Anpad (2006). Nesta versão, que se beneficia dos comentários de revisores anônimos, procuro reforçar e tornar mais clara a defesa do argumento.

${ }^{1}$ Foram adotadas neste texto as traduções de Fonseca (2003, p.60) para as designações das estratégias de Oliver (1991), com exceção de desafio, que parece mais indicada para designar uma das táticas, challenge, e não a estratégia, defiance. Para esta, preferi adotar como tradução a palavra desobediência.
} 